\title{
Models of cell signaling uncover molecular mechanisms of high-risk neuroblastoma and predict disease outcome
}

\author{
Marta R. Hidalgo', Alicia Amadoz ${ }^{2}$, Cankut Çubuk1, José Carbonell-Caballero ${ }^{3}$ and Joaquín Dopazo ${ }^{1,4,5^{*}}$ (D)
}

\begin{abstract}
Background: Despite the progress in neuroblastoma therapies the mortality of high-risk patients is still high (40-50\%) and the molecular basis of the disease remains poorly known. Recently, a mathematical model was used to demonstrate that the network regulating stress signaling by the c-Jun $\mathrm{N}$-terminal kinase pathway played a crucial role in survival of patients with neuroblastoma irrespective of their MYCN amplification status. This demonstrates the enormous potential of computational models of biological modules for the discovery of underlying molecular mechanisms of diseases.
\end{abstract}

Results: Since signaling is known to be highly relevant in cancer, we have used a computational model of the whole cell signaling network to understand the molecular determinants of bad prognostic in neuroblastoma. Our model produced a comprehensive view of the molecular mechanisms of neuroblastoma tumorigenesis and progression.

Conclusion: We have also shown how the activity of signaling circuits can be considered a reliable model-based prognostic biomarker.

Reviewers: This article was reviewed by Tim Beissbarth, Wenzhong Xiao and Joanna Polanska. For the full reviews, please go to the Reviewers' comments section.

\section{Background}

Neuroblastoma is a tumor derived from primitive cells of the sympathetic nervous system that, despite advances in its treatment still has a poor survival for high-risk patients [1]. Risk groups are defined according to disease stage, patient age, and MYCN amplification status [2]. Although the use of biomarkers has demonstrated clinical utility, they represent statistical associations to clinical parameters and frequently lack any mechanistic relationship with the molecular mechanisms responsible for tumorigenesis or therapeutic response. On the contrary, signaling pathways control cell behavior and constitute the mechanisms that ultimately determine the fate of cancer cells. In fact, in a recent study, a mathematical model of the JNK signaling dynamics has demonstrated that this pathway plays a

\footnotetext{
* Correspondence: joaquin.dopazo@juntadeandalucia.es

${ }^{1}$ Clinical Bioinformatics Area, Fundación Progreso y Salud (FPS), CDCA,

Hospital Virgen del Rocio, c/Manuel Siurot s/n, 41013 Sevilla, Spain

${ }^{4}$ Functional Genomics Node (INB). FPS, Hospital Virgen del Rocio, c/Manuel

Siurot s/n, 41013 Sevilla, Spain

Full list of author information is available at the end of the article
}

major role in neuroblastoma [3]. Moreover, the study demonstrated that the activity of the JNK signaling pathway showed a more significant correlation with patient survival than those shown by any of their constituent genes. Therefore, these results revealed how JNK signaling dynamics represents an innovative type of model-based biomarker that efficiently predicts neuroblastoma patient prognostic across different individual molecular backgrounds defined by conventional single gene biomarkers. This concept has been recently extended to other cancers where computational models demonstrated that the activity of specific circuits of signaling pathways related to diverse cancer hallmarks [4] provided a robust prediction of patient survival [5]. Moreover, the accuracy of the prediction obtained using the activity of the signaling circuit surpassed the conventional predictions based solely on the activities of their constituent proteins, clearly demonstrating that not only the levels of signaling individual nodes but also the network topology of the signaling circuit and thus the nonlinear properties of a signal response should ideally be captured in a biomarker in order 
to produce a robust prediction of patient outcome [5]. Furthermore, this type of models have proven to be superior to other pathway-based models [6].

Here, we have used generalized computational models covering all the signaling activity related with cancer hallmarks and other cancer-related signaling pathways. Such computational models use gene expression data to produce a realistic estimation of signaling circuit activity within pathways [5], which can subsequently be used to discover the molecular mechanisms behind the differences between patients with and without $M Y C N$ amplification as well as to uncover the determinants of survival in neuroblastoma patients.

\section{Results}

\section{Data processing}

A gene expression matrix with expression values quantified as $\log _{2}(1+$ FPKM $)$ were downloaded from the GEO database. In order to correct batch effect the COMBAT [7] method was used. The expression values were further normalized between 0 and 1 to run the software implementing the models.

\section{Molecular mechanisms behind the MYCN amplification biomarker}

Since $M Y C N$ amplification is a known biomarker of bad prognostic [2] we were interested in understanding the molecular basis of such pathological phenotype. To achieve so, we carried out a differential signaling activity test comparing patients with $M Y C N$ amplification to those ones lacking this biomarker. Overall, our results document extensive differences at the level of signaling activity between patients with different $M Y C N$ amplification status. Specifically, patients with $M Y C N$ amplification seem to inhibit the $J N K$ pathway, necessary for cell apoptosis, confirming in this way previous observations [3]. The mechanism for JNK inhibition seems complex and involves the participation of several important pathways such as Ras pathway, Apoptosis, MAPK signaling pathway and NF-kappa B signaling pathways, among others (see Table 1). In particular, the
NF-kappa B signaling pathway significantly deactivates three signalling circuits ending in the proteins CCL19, $C C L 21$ and GADD45B, as depicted in Fig. 1. Also, the MAPK signaling pathway, together with the circuits that transduce signal to MAPK8 within Ras, Fc epsilon RI and $c A M P$ signaling pathways, seems to play an important role as mechanisms for the inactivation of the JNK pathway.

Another well-defined mechanism characteristic of patients with $M Y C N$ amplification seems to be defective DNA repair. Again, the mechanism seems complex and mediated by many different pathways, which is not surprising, given that DNA repair must be a robust mechanism. A total of 5 circuits belonging to the pathways Jak-STAT, MAPK, ErbB, Wnt and Hippo signaling pathways present a highly significant deactivation in patients with $M Y C N$ amplification (see Table 2). As an example, Fig. 2 shows the inhibition in the JACK-STAT pathway. Remarkably, the effector of all these circuits is the $M Y C$ protein, which seems to be the counterpart of $M Y C N$ in patients with $M Y C N$-nonamplified neuroblastomas. In fact, BMI1 expression, a gene, whose suppression resulted in significantly greater inhibition of cell growth, correlated with $M Y C N$ levels in $M Y C N$-amplified neuroblastoma cells, and with $M Y C$ levels in the $M Y C N$-nonamplified group [8].

The rest of processes that can be considered as cancer hallmarks [4] have an inconclusive distribution between the two groups of neuroblastomas. For example, angiogenesis seem to be activated in MYCN-amplified patients through circuits in Apoptosis, cGMP-PKG and PI3K-Akt signaling pathways but other circuits in other pathways (HIF-1, NF-kappa B and P53) seem to deactivate it (see Table 3 ).

These results documents that while patients with $M Y C N$ amplification have characteristic signaling activities that trigger processes which contribute to bad prognostic, such as the inhibition of the JNK pathway or potentially defective DNA repair, much of the cancer hallmarks are not exclusive of this group. Therefore we investigate what are the mechanisms behind patient

Table 1 Circuits that deactivate the JNK cascade in patients with MYCN amplification

\begin{tabular}{lllll}
\hline Circuit (Pathway and effector protein) & Status & FDR p-value & GO ID & GO Definition \\
\hline Ras signaling pathway: MAPK8 & DOWN & $4.31 \mathrm{E}-29$ & GO:0007254 & JNK cascade \\
Fc epsilon RI signaling pathway: MAPK8 & DOWN & $1.23 \mathrm{E}-15$ & GO:0007254 & JNK cascade \\
CAMP signaling pathway: MAPK8 & DOWN & $4.72 \mathrm{E}-08$ & GO:0007254 & JNK cascade \\
Apoptosis: GADD45G & DOWN & $1.07 \mathrm{E}-29$ & GO:0046330 & positive regulation of JNK cascade \\
MAPK signaling pathway: MAP 4 K2 & DOWN & $1.68 E-24$ & GO:0046330 & positive regulation of JNK cascade \\
NF-kappa B signaling pathway: CCL19 & DOWN & $2.36 E-22$ & GO:0046330 & positive regulation of JNK cascade \\
NF-kappa B signaling pathway: GADD45B & DOWN & $3.83 E-21$ & GO:0046330 & positive regulation of JNK cascade \\
NF-kappa B signaling pathway: CCL21 & DOWN & $8.43 E-16$ & GO:0046330 & positive regulation of JNK cascade \\
p53 signaling pathway: GADD45G & UP & $1.70 E-07$ & GO:0046330 & positive regulation of JNK cascade \\
\hline
\end{tabular}




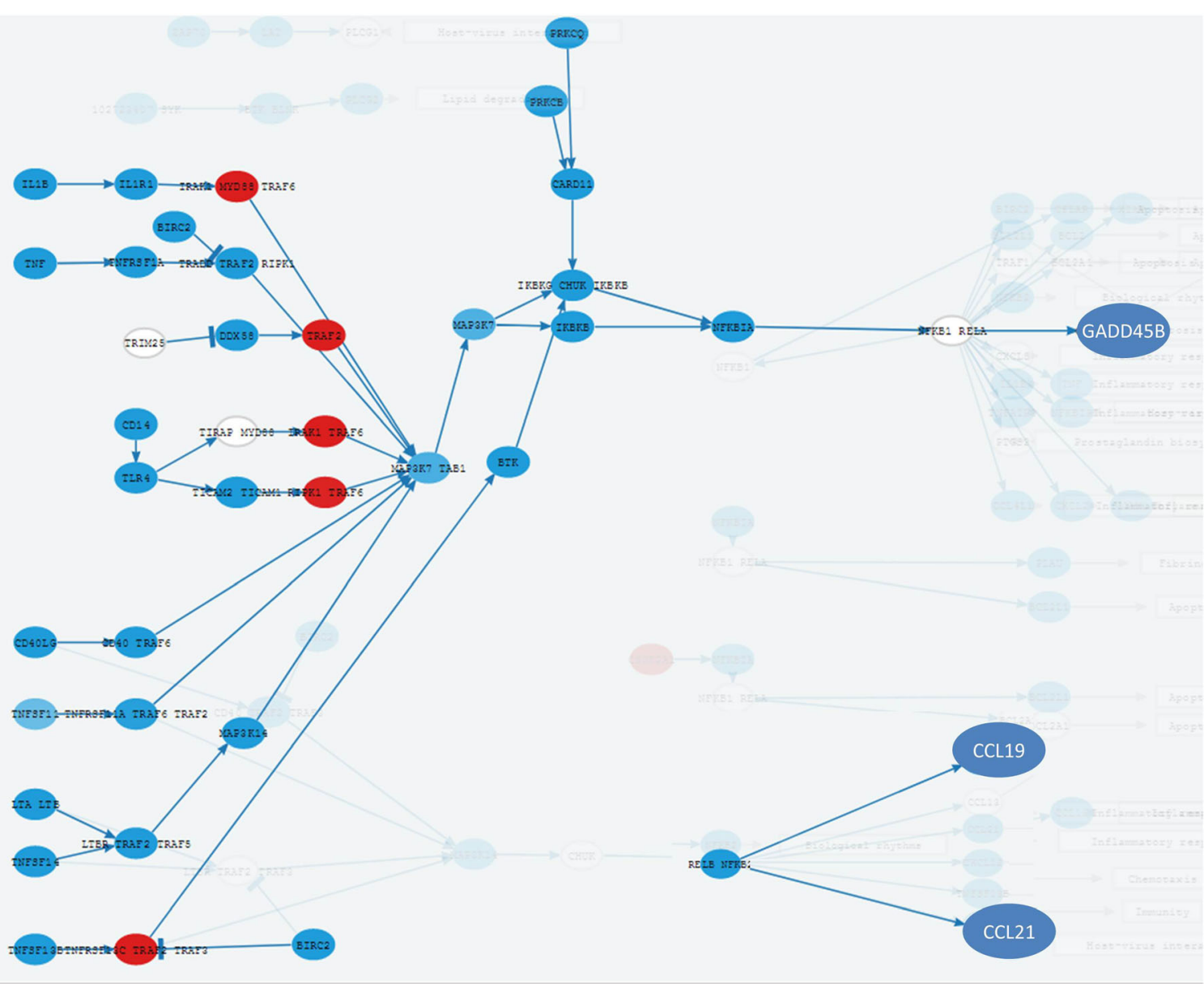

Fig. 1 Three signaling circuits ending in the proteins CCL19, CCL21 and GADD45B highlighted within the whole NF-kappa B signaling pathway. The circuits are significantly deactivated in patients with MYCN amplification when compared to patients without such biomarker. The results and the representation have been obtained with the program HiPathia [5]. Blue and red nodes indicate genes downregulated and upregulated, respectively. Blue arrows depict the circuits in which signal transduction is inhibited

Table 2 Circuits that deactivate DNA repair and related cell functions

\begin{tabular}{lllll}
\hline Circuit (Pathway and effector protein) & Status & FDR p-value & GO ID & GO Definition \\
\hline Jak-STAT signaling pathway: MYC & DOWN & $1.94 \mathrm{E}-32$ & $\mathrm{GO} 2001022$ & positive regulation of response to DNA damage stimulus \\
MAPK signaling pathway: MYC & DOWN & $1.39 \mathrm{E}-26$ & $\mathrm{GO} 2001022$ & positive regulation of response to DNA damage stimulus \\
ErbB signaling pathway: MYC & DOWN & $7.15 \mathrm{E}-24$ & $\mathrm{GO} 2001022$ & positive regulation of response to DNA damage stimulus \\
Wnt signaling pathway: MYC & DOWN & $7.78 \mathrm{E}-22$ & $\mathrm{GO} 2001022$ & positive regulation of response to DNA damage stimulus \\
Hippo signaling pathway: MYC & DOWN & $7.12 \mathrm{E}-13$ & $\mathrm{GO}: 2001022$ & positive regulation of response to DNA damage stimulus \\
Jak-STAT signaling pathway: MYC & DOWN & $1.94 \mathrm{E}-32$ & $\mathrm{GO}: 0006338$ & chromatin remodeling \\
MAPK signaling pathway: MYC & DOWN & $1.39 \mathrm{E}-26$ & $\mathrm{GO}: 0006338$ & chromatin remodeling \\
ErbB signaling pathway: MYC & DOWN & $7.15 \mathrm{E}-24$ & $\mathrm{GO}: 0006338$ & chromatin remodeling \\
Wnt signaling pathway: MYC & DOWN & $7.78 \mathrm{E}-22$ & $\mathrm{GO}: 0006338$ & chromatin remodeling \\
Hippo signaling pathway: MYC & DOWN & $7.12 \mathrm{E}-13$ & $\mathrm{GO} 0006338$ & chromatin remodeling \\
\hline
\end{tabular}




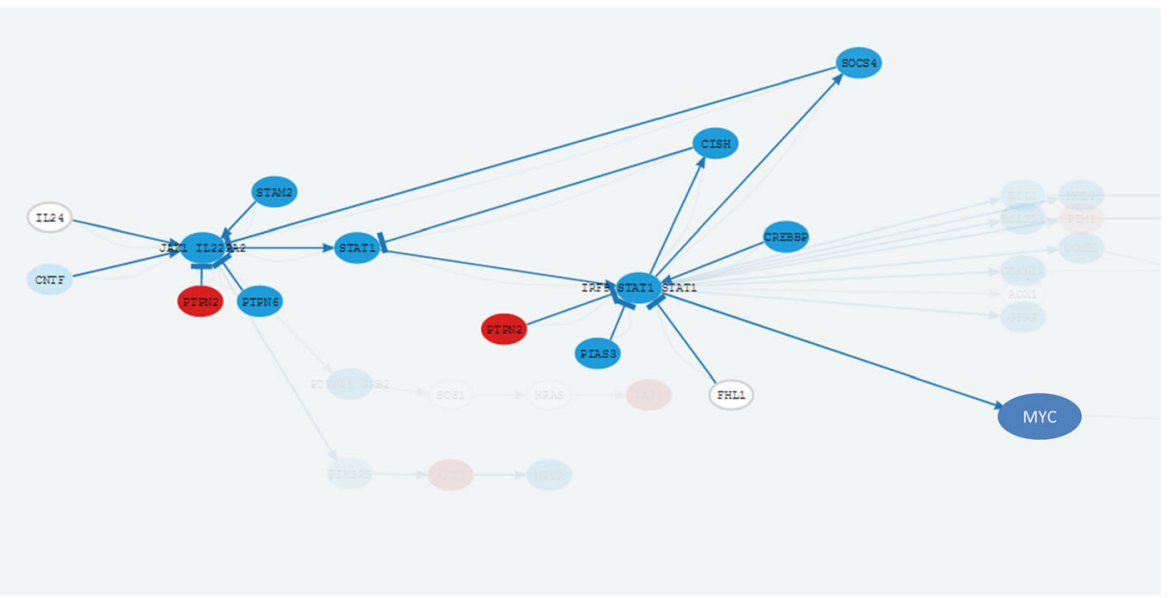

Fig. 2 JACK-STAT signaling pathway with the circuit ending in MYC protein. That triggers response to DNA damage. Significantly (FDR-adj. $p$-value $=1.94 \times 10^{-32}$ ) deactivated in patients with MYCN amplification. The results and the representation have been obtained with the program HiPathia [5]. Blue and red nodes indicate genes downregulated and upregulated, respectively, in patients with MYCN amplification. The deactivations of nodes that transmit the signal concomitantly with the activation of signal repressor genes strongly suggest the actuation of a regulatory program to inhibit the signal

mortality irrespective of $M Y C N$ amplification status in the following section.

\section{Molecular mechanisms that determine patient survival}

For each circuit, patients irrespective of its $M Y C N$ amplification status were divided into two groups: $10 \%$ highest circuit activity patients and the rest and K-M curves were plotted and tests were applied to detect significant differences in survival. The same procedure was repeated with the $10 \%$ lowest circuit activity patients (see Methods).

We were able to detect numerous processes activated and deactivated with a strong significant association to survival that could easily be associated to known cancer hallmarks (Table 4). Inhibition of apoptosis is a recognized cancer hallmark, whose mechanism of deactivation is disclosed here. Negative regulation of apoptosis is induced in patients with activated signaling circuits in the PI3K-Akt signaling pathway (PI3K-Akt signaling pathway: $B C L 2 L 1$ ). Apoptosis is massively inhibited through the inhibition of several circuits in the following pathways: Apoptosis (see Fig. 3a for an example), ErbB, Hippo, Jak-STAT, MAPK, mTOR, NF-kappa B, NOD-like receptor, PI3K-Akt, Ras, T cell receptor, Tight junction, Toll-like receptor and Wnt (Table 4). Interestingly, 5 circuits belonging to pathways Apoptosis, Fc epsilon RI, NF-kappa B, MAPK and Ras (see Table 4) are inhibiting apoptosis via JNK inhibition, which provide a mechanism for this observation [3]. Patients with the corresponding activations or deactivations of these circuits that ultimately deactivate apoptosis have a significantly higher mortality (see Table 4).

The patients with activation in circuit of the p53 signaling pathway ending in the THBS1 protein, related with metastasis in gastric cancers [9], show a significantly higher mortality (FDR-adj. p-val $=3.03 \times 10^{-7}$ ) prognostic (see Fig. 3b). The prognostic is similar for patients with high activity of the circuit of the Wnt signaling pathway ending in the transcription factor NFATc1 (FDR-adj. p-val $=1.99 \times 10^{-6}$ ), also related to tumorigenesis [10]. Both circuits seem to trigger metastasis-related cell responses.

Table 3 Circuits with different effects on angiogenesis

\begin{tabular}{lllll}
\hline Circuit (Pathway and effector protein) & Status & FDR p-value & GO ID & GO Definition \\
\hline Apoptosis: FASLG & DOWN & $1.44 \mathrm{E}-22$ & GO:0016525 & negative regulation of angiogenesis \\
PI3K-Akt signaling pathway: FASLG & DOWN & $1.18 \mathrm{E}-21$ & GO:0016525 & negative regulation of angiogenesis \\
p53 signaling pathway: THBS1 & UP & $4.43 \mathrm{E}-09$ & $\mathrm{GO}: 0016525$ & negative regulation of angiogenesis \\
CGMP-PKG signaling pathway: GTF21 & DOWN & $3.40 \mathrm{E}-06$ & $\mathrm{GO}: 0016525$ & negative regulation of angiogenesis \\
HIF-1 signaling pathway: TEK & DOWN & $8.85 \mathrm{E}-27$ & $\mathrm{GO}: 0045766$ & positive regulation of angiogenesis \\
HIF-1 signaling pathway: VEGFA & DOWN & $2.20 \mathrm{E}-25$ & $\mathrm{GO}: 0045766$ & positive regulation of angiogenesis \\
NF-kappa B signaling pathway: PLCG1 & DOWN & $3.62 \mathrm{E}-17$ & GO:0045766 & positive regulation of angiogenesis \\
\hline
\end{tabular}


Table 4 Circuits significantly associated to bad prognostic

\begin{tabular}{|c|c|c|c|c|c|}
\hline $\begin{array}{l}\text { Circuit (Pathway and effector } \\
\text { protein) }\end{array}$ & Status & FDR p-val & GO ID & GO definition & Cancer hallmark \\
\hline $\begin{array}{l}\text { PI3K-Akt signaling pathway: } \\
\text { BCL2L1 }\end{array}$ & UP & $5.13 \mathrm{E}-07$ & GO:1900118 & negative regulation of execution phase of apoptosis & $\begin{array}{l}\text { Apoptosis } \\
\text { inhibition }\end{array}$ \\
\hline Axon guidance: PAK4 & UP & 1.47E-05 & GO:2001271 & $\begin{array}{l}\text { negative regulation of cysteine-type endopeptidase activity } \\
\text { involved in execution phase of apoptosis }\end{array}$ & $\begin{array}{l}\text { Apoptosis } \\
\text { inhibition }\end{array}$ \\
\hline $\begin{array}{l}\text { PI3K-Akt signaling pathway: } \\
\text { BCL2L1 }\end{array}$ & UP & 0.000159 & GO:1900118 & negative regulation of execution phase of apoptosis & $\begin{array}{l}\text { Apoptosis } \\
\text { inhibition }\end{array}$ \\
\hline $\begin{array}{l}\text { Adherens junction: LEF1 } \\
\text { CTNNB1 }\end{array}$ & DOWN & 7.35E-07 & GO:0043065 & positive regulation of apoptotic process & $\begin{array}{l}\text { Apoptosis } \\
\text { inhibition }\end{array}$ \\
\hline Apoptosis: BCL2L11 & DOWN & $2.28 \mathrm{E}-11$ & GO:2000271 & positive regulation of fibroblast apoptotic process & $\begin{array}{l}\text { Apoptosis } \\
\text { inhibition }\end{array}$ \\
\hline Apoptosis: FAS & DOWN & $3.43 \mathrm{E}-06$ & GO:0043065 & positive regulation of apoptotic process & $\begin{array}{l}\text { Apoptosis } \\
\text { inhibition }\end{array}$ \\
\hline Apoptosis: FASLG & DOWN & $9.88 \mathrm{E}-11$ & GO:2000353 & positive regulation of endothelial cell apoptotic process & $\begin{array}{l}\text { Apoptosis } \\
\text { inhibition }\end{array}$ \\
\hline Apoptosis: GADD45G & DOWN & $5.11 \mathrm{E}-11$ & GO:0043065 & positive regulation of apoptotic process & $\begin{array}{l}\text { Apoptosis } \\
\text { inhibition }\end{array}$ \\
\hline Apoptosis: TP53 & DOWN & 2.07E-06 & GO:0090200 & $\begin{array}{l}\text { positive regulation of release of cytochrome c from } \\
\text { mitochondria }\end{array}$ & $\begin{array}{l}\text { Apoptosis } \\
\text { inhibition }\end{array}$ \\
\hline Axon guidance: NCK1 PAK4 & DOWN & 0.0003919 & GO:1902237 & $\begin{array}{l}\text { positive regulation of endoplasmic reticulum stress-induced } \\
\text { intrinsic apoptotic signaling pathway }\end{array}$ & $\begin{array}{l}\text { Apoptosis } \\
\text { inhibition }\end{array}$ \\
\hline ErbB signaling pathway: MYC & DOWN & $6.05 \mathrm{E}-07$ & GO:0043280 & $\begin{array}{l}\text { positive regulation of cysteine-type endopeptidase activity in- } \\
\text { volved in apoptotic process }\end{array}$ & $\begin{array}{l}\text { Apoptosis } \\
\text { inhibition }\end{array}$ \\
\hline Hippo signaling pathway: MYC & DOWN & 0.0006402 & GO:0043280 & $\begin{array}{l}\text { positive regulation of cysteine-type endopeptidase activity in- } \\
\text { volved in apoptotic process }\end{array}$ & $\begin{array}{l}\text { Apoptosis } \\
\text { inhibition }\end{array}$ \\
\hline $\begin{array}{l}\text { Jak-STAT signaling pathway: } \\
\text { MYC }\end{array}$ & DOWN & $2.38 \mathrm{E}-14$ & GO:0043280 & $\begin{array}{l}\text { positive regulation of cysteine-type endopeptidase activity in- } \\
\text { volved in apoptotic process }\end{array}$ & $\begin{array}{l}\text { Apoptosis } \\
\text { inhibition }\end{array}$ \\
\hline MAPK signaling pathway: MYC & DOWN & $1.46 \mathrm{E}-10$ & GO:0043280 & $\begin{array}{l}\text { positive regulation of cysteine-type endopeptidase activity in- } \\
\text { volved in apoptotic process }\end{array}$ & $\begin{array}{l}\text { Apoptosis } \\
\text { inhibition }\end{array}$ \\
\hline MAPK signaling pathway: STK3 & DOWN & 2.47E-07 & GO:0043065 & positive regulation of apoptotic process & $\begin{array}{l}\text { Apoptosis } \\
\text { inhibition }\end{array}$ \\
\hline mTOR signaling pathway: RPS6 & DOWN & $2.77 \mathrm{E}-11$ & GO:0043065 & positive regulation of apoptotic process & $\begin{array}{l}\text { Apoptosis } \\
\text { inhibition }\end{array}$ \\
\hline $\begin{array}{l}\text { NF-kappa B signaling pathway: } \\
\text { GADD45B }\end{array}$ & DOWN & $5.23 \mathrm{E}-07$ & GO:0043065 & positive regulation of apoptotic process & $\begin{array}{l}\text { Apoptosis } \\
\text { inhibition }\end{array}$ \\
\hline $\begin{array}{l}\text { NOD-like receptor signaling } \\
\text { pathway: PYCARD CASP1 }\end{array}$ & DOWN & 7.86E-05 & GO:0043280 & $\begin{array}{l}\text { positive regulation of cysteine-type endopeptidase activity in- } \\
\text { volved in apoptotic process }\end{array}$ & $\begin{array}{l}\text { Apoptosis } \\
\text { inhibition }\end{array}$ \\
\hline $\begin{array}{l}\text { PI3K-Akt signaling pathway: } \\
\text { BCL2L11 }\end{array}$ & DOWN & 0.0003220 & GO:2000271 & positive regulation of fibroblast apoptotic process & $\begin{array}{l}\text { Apoptosis } \\
\text { inhibition }\end{array}$ \\
\hline $\begin{array}{l}\text { PI3K-Akt signaling pathway: } \\
\text { FASLG }\end{array}$ & DOWN & $2.56 \mathrm{E}-12$ & GO:2000353 & positive regulation of endothelial cell apoptotic process & $\begin{array}{l}\text { Apoptosis } \\
\text { inhibition }\end{array}$ \\
\hline $\begin{array}{l}\text { PI3K-Akt signaling pathway: } \\
\text { RPS6 }\end{array}$ & DOWN & $3.43 \mathrm{E}-06$ & GO:0043065 & positive regulation of apoptotic process & $\begin{array}{l}\text { Apoptosis } \\
\text { inhibition }\end{array}$ \\
\hline $\begin{array}{l}\text { Ras signaling pathway: STK4 } \\
\text { STK4 }\end{array}$ & DOWN & 0.0001864 & GO:0043065 & positive regulation of apoptotic process & $\begin{array}{l}\text { Apoptosis } \\
\text { inhibition }\end{array}$ \\
\hline $\begin{array}{l}\text { T cell receptor signaling } \\
\text { pathway: CD40LG }\end{array}$ & DOWN & 0.0002348 & GO:2000353 & positive regulation of endothelial cell apoptotic process & $\begin{array}{l}\text { Apoptosis } \\
\text { inhibition }\end{array}$ \\
\hline $\begin{array}{l}\text { Tight junction: TJP1 CTNNB1 } \\
\text { CTNNA1 }\end{array}$ & DOWN & 0.0004428 & GO:0043065 & positive regulation of apoptotic process & $\begin{array}{l}\text { Apoptosis } \\
\text { inhibition }\end{array}$ \\
\hline $\begin{array}{l}\text { Toll-like receptor signaling } \\
\text { pathway: CCL5 }\end{array}$ & DOWN & 1.89E-08 & GO:0070234 & positive regulation of $\mathrm{T}$ cell apoptotic process & $\begin{array}{l}\text { Apoptosis } \\
\text { inhibition }\end{array}$ \\
\hline Wnt signaling pathway: MYC & DOWN & $5.12 \mathrm{E}-05$ & GO:0043280 & $\begin{array}{l}\text { positive regulation of cysteine-type endopeptidase activity in- } \\
\text { volved in apoptotic process }\end{array}$ & $\begin{array}{l}\text { Apoptosis } \\
\text { inhibition }\end{array}$ \\
\hline
\end{tabular}

Apoptosis 
Table 4 Circuits significantly associated to bad prognostic (Continued)

\begin{tabular}{|c|c|c|c|c|c|}
\hline $\begin{array}{l}\text { Circuit (Pathway and effector } \\
\text { protein) }\end{array}$ & Status & FDR p-val & $\mathrm{GO} I \mathrm{D}$ & GO definition & Cancer hallmark \\
\hline & & & & & inhibition \\
\hline Apoptosis: GADD45G & DOWN & $5.11 \mathrm{E}-11$ & GO:0046330 & positive regulation of JNK cascade & $\begin{array}{l}\text { Apoptosis } \\
\text { inhibition via } \\
\text { JNK }\end{array}$ \\
\hline $\begin{array}{l}\text { Fc epsilon RI signaling pathway: } \\
\text { MAPK8 }\end{array}$ & DOWN & $1.78 \mathrm{E}-07$ & GO:0007254 & JNK cascade & $\begin{array}{l}\text { Apoptosis } \\
\text { inhibition via } \\
\text { JNK }\end{array}$ \\
\hline $\begin{array}{l}\text { NF-kappa B signaling pathway: } \\
\text { GADD45B }\end{array}$ & DOWN & $5.23 \mathrm{E}-07$ & GO:0046330 & positive regulation of JNK cascade & $\begin{array}{l}\text { Apoptosis } \\
\text { inhibition via } \\
\text { JNK }\end{array}$ \\
\hline $\begin{array}{l}\text { MAPK signaling pathway: MAP } \\
4 \text { K2 }\end{array}$ & DOWN & $9.26 \mathrm{E}-05$ & GO:0046330 & positive regulation of JNK cascade & $\begin{array}{l}\text { Apoptosis } \\
\text { inhibition via } \\
\text { JNK }\end{array}$ \\
\hline $\begin{array}{l}\text { NF-kappa B signaling pathway: } \\
\text { CCL21 }\end{array}$ & DOWN & 0.0001040 & GO:0046330 & positive regulation of JNK cascade & $\begin{array}{l}\text { Apoptosis } \\
\text { inhibition via } \\
\text { JNK }\end{array}$ \\
\hline Ras signaling pathway: MAPK8 & DOWN & 0.0003003 & GO:0007254 & JNK cascade & $\begin{array}{l}\text { Apoptosis } \\
\text { inhibition via } \\
\text { JNK }\end{array}$ \\
\hline $\begin{array}{l}\text { Neurotrophin signaling pathway: } \\
\text { BAX }\end{array}$ & UP & $3.02 \mathrm{E}-05$ & GO:1990117 & B cell receptor apoptotic signaling pathway & $\begin{array}{l}\text { Reduced } \\
\text { immune } \\
\text { response }\end{array}$ \\
\hline $\begin{array}{l}\text { Neurotrophin signaling pathway: } \\
\text { BAX }\end{array}$ & UP & $3.02 \mathrm{E}-05$ & GO:0001783 & B cell apoptotic process & $\begin{array}{l}\text { Reduced } \\
\text { immune } \\
\text { response }\end{array}$ \\
\hline p53 signaling pathway: THBS1 & UP & $3.04 \mathrm{E}-07$ & GO:0030335 & positive regulation of cell migration & Metastasis \\
\hline Wnt signaling pathway: NFATC1 & UP & 1.99E-06 & GO:0016477 & cell migration & Metastasis \\
\hline $\begin{array}{l}\text { PI3K-Akt signaling pathway: } \\
\text { TP53 }\end{array}$ & UP & 1.17E-06 & GO:0045944 & $\begin{array}{l}\text { positive regulation of transcription from RNA polymerase II } \\
\text { promoter }\end{array}$ & Proliferation \\
\hline Ras signaling pathway: ELK1 & UP & $1.38 \mathrm{E}-06$ & GO:0045944 & $\begin{array}{l}\text { positive regulation of transcription from RNA polymerase II } \\
\text { promoter }\end{array}$ & Proliferation \\
\hline Wnt signaling pathway: NFATC1 & UP & $1.99 \mathrm{E}-06$ & GO:0045944 & $\begin{array}{l}\text { positive regulation of transcription from RNA polymerase II } \\
\text { promoter }\end{array}$ & Proliferation \\
\hline $\begin{array}{l}\text { AMPK signaling pathway: } \\
\text { EIF4EBP1 }\end{array}$ & UP & 0.0001405 & GO:0045947 & negative regulation of translational initiation & Proliferation \\
\hline ErbB signaling pathway: ELK1 & UP & 0.0004442 & GO:0045944 & $\begin{array}{l}\text { positive regulation of transcription from RNA polymerase II } \\
\text { promoter }\end{array}$ & Proliferation \\
\hline Apoptosis: FASLG & DOWN & $9.88 \mathrm{E}-11$ & GO:0000122 & $\begin{array}{l}\text { negative regulation of transcription from RNA polymerase II } \\
\text { promoter }\end{array}$ & Proliferation \\
\hline $\begin{array}{l}\text { PI3K-Akt signaling pathway: } \\
\text { FASLG }\end{array}$ & DOWN & $2.56 \mathrm{E}-12$ & GO:0016525 & negative regulation of angiogenesis & Angiogenesis \\
\hline $\begin{array}{l}\text { HIF-1 signaling pathway: } \\
\text { ANGPT1 }\end{array}$ & DOWN & $1.41 \mathrm{E}-11$ & GO:0016525 & negative regulation of angiogenesis & Angiogenesis \\
\hline Apoptosis: FASLG & DOWN & $9.88 \mathrm{E}-11$ & GO:0016525 & negative regulation of angiogenesis & Angiogenesis \\
\hline
\end{tabular}

There are three circuits that activate angiogenesis via the inhibition of the pro-apoptotic factor Fas ligand (that is inversely correlated with angiogenesis) [11] and the angiogenesis modulator ANGPT1 [12] which appear downregulated, and consequently promoting angiogenesis, in patients with significantly high mortality (see Table 4). An example is the inhibition FASLG via the corresponding circuit in the PI3K-Atk signaling pathway (see Fig. 3c).
Interestingly, we found specific apoptosis induction of $\mathrm{B}$ cells mediated by the known apoptotic protein $B A X$ [13] through the Neurotrophin signaling pathway. The activation of this circuit, which seems to be a strategy to evade immune response, is significantly associated to higher mortality in patients (FDR-adj. p-val $=3.02 \times 10^{-5}$; see Fig. $3 \mathrm{~d}$ ).

We also tried to find the molecular drivers of bad prognostic specific of patients with $M Y C N$ amplifications. 


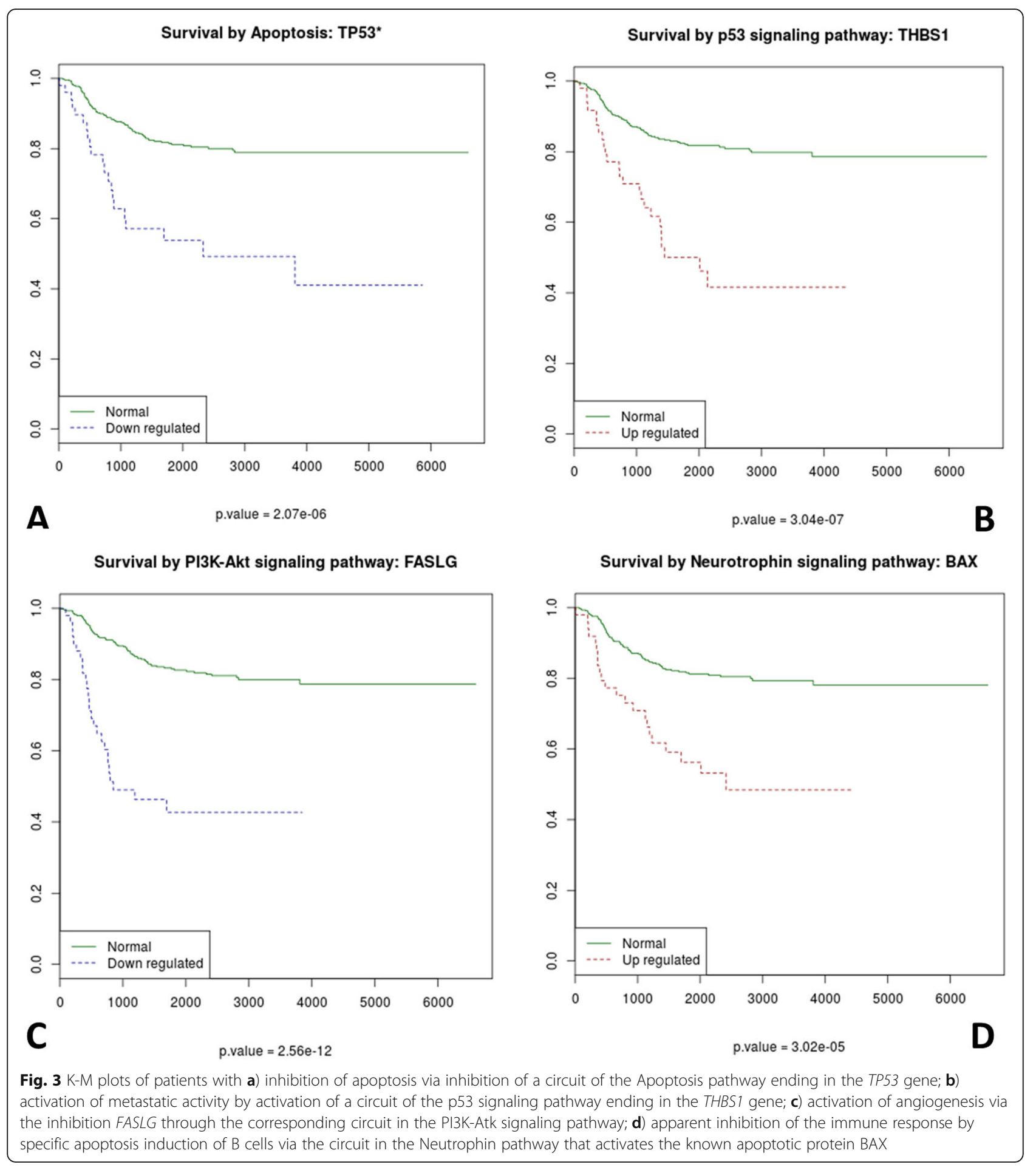

Only two circuits, Adipocytokine: PTPN11 and cAMP: $A F D N$ are significantly associated to bad prognostic (FDR-adj. $p$-values of 0.027 and 0.008 , respectively; see Fig. 4). One of the effector proteins, PTPN11 has been implicated in mitogenic activation, metabolic control, transcription regulation, and cell migration [14]. The other effector protein, $A F D N$, is the fusion partner of acute lymphoblastic leukemia $(A L L-1)$ gen involved in acute myeloid leukemias with $\mathrm{t}(6 ; 11)(\mathrm{q} 27 ; \mathrm{q} 23)$ translocation, with a known role in cell adhesion [15].

\section{Conclusions}

It has recently been demonstrated that model-based biomarker based on the activity of the JNK pathway 

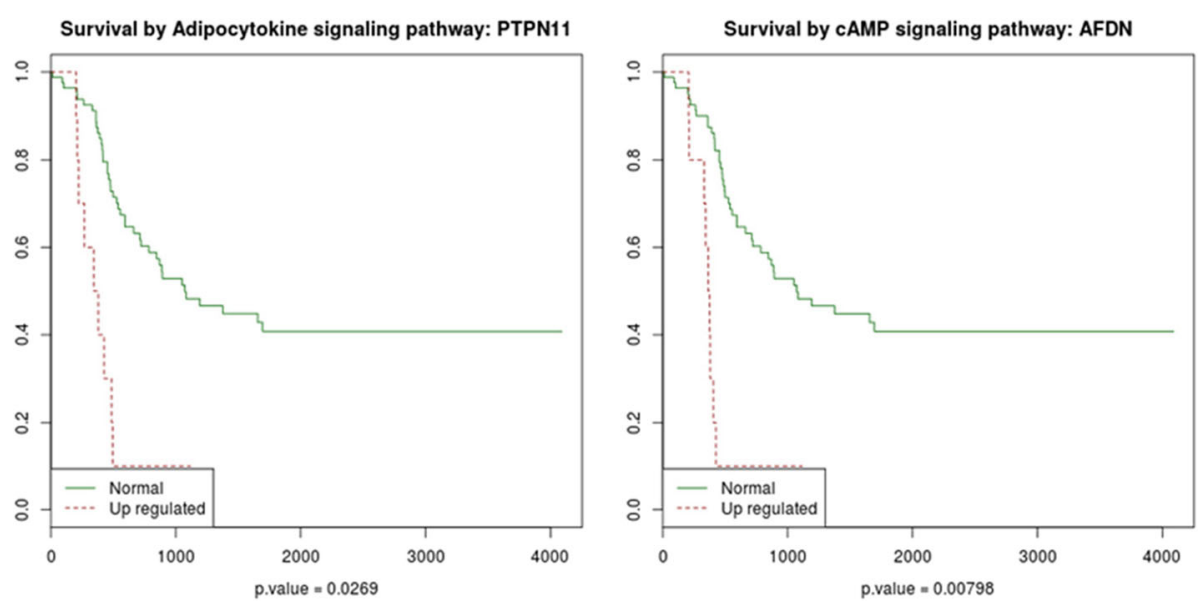

Fig. 4 K-M plots of survival of patients with MYCN amplification which have downregulated Adipocytokine: PTPN11 (left) and CAMP: AFDN (right) signaling circuits

robustly stratified neuroblastoma patients across different molecular backgrounds [3]. Computational models have already been used to provide an understanding of the dynamics of one or a few specific signaling pathways [16-18], however, the availability of comprehensive pathway-wide models [5] that transform decontextualized transcriptomics gene expression data into signaling activities, which in turn trigger cell functions that can be linked to cancer hallmarks, provide a quantitative framework to identify neuroblastoma functional drivers. Thus, we were not only able to reproduce the results of previous modeling studies that linked the inability of activating the JNK pathway to neuroblastoma bad prognostic but also to discover the pathways upstream responsible of its inhibition. Moreover, we were able to find the involvement of numerous pathways in the activation or deactivation of numerous cell functionalities responsible of proliferation, angiogenesis, metastasis and apoptosis inhibition, four well-known cancer hallmarks. Interestingly, some of these functionalities are coordinately triggered in a way that results in a neoplastic phenotype. Although further research needs to be done to elucidate what the ultimate regulatory drivers behind such functional changes are, the widespread deregulation observed in cancer [19] acting over the wiring constrictions of the human signaling pathways must play an important role.

The use of models that quantify cell behavioral outcomes provides a unique opportunity to understand the molecular mechanisms of cancer development and progression [20], and ultimately pave the way to suggest highly specific, individualized therapeutic interventions [21, 22].

\section{Methods}

Data source and data preprocessing

The matrix GSE49711_SEQC_NB_TUC_G_log2.txt, with gene expression levels estimated by Cufflinks [23] and quantified as $\log _{2}(1+\mathrm{FPKM})$, was downloaded from the GEO database. Batch effect was corrected with COMBAT [7]. Finally, the values were normalized between 0 and 1.

\section{Signaling circuit activity model}

Circuit activities are modelled from gene expression values as described in [5]. Briefly, KEGG pathways [24] are used to define circuits connecting receptor proteins to effector proteins. Specifically, we are using effector circuits that connect effector proteins to all the receptor proteins that can transduce the signal to them (see Additional file 1). A total of 98 KEGG pathways involving a total of 3057 genes that compose 4726 nodes were used to define a total of 1287 signaling circuits. Normalized gene expression values are used as proxies of protein activity [25-27]. The signal transmission is estimated by starting with an initial signal of 1 , which is propagated along the nodes of the signaling circuits according to the following recursive rule:

$$
S_{n}=v_{n} \cdot\left(1-\prod_{s_{a} \in A}\left(1-s_{a}\right)\right) \cdot \prod_{s_{i} \in I}\left(1-s_{i}\right)
$$

Where $S_{n}$ is the signal intensity for the current node $n$, $v_{n}$ is its normalized gene expression value, $A$ is the set of activation signals $\left(s_{a}\right)$, arriving to the current node from activation edges, $I$ is the set of inhibitory signals $\left(s_{i}\right)$ arriving to the node from inhibition edges [5]. In addition to circuit activities, the signal received by specific cell functions (according to either Gene Ontology [28] or Uniprot [29] definitions), triggered by more than one circuit, can also be estimated (See Additional file 2). This approach has proven to be superior to other types of pathway-based models [6]. 


\section{Statistical significance of circuit activities}

Similarly to normalized gene expression values, circuit activities are measurements that do not make sense alone but rather in the context of a comparison. Thus, circuit activities can be used to compare conditions in the same way than gene expression values are used in a differential gene expression test. A Wilcoxon test is applied to assess the significance of the observed differences in circuit activities when two conditions are compared (e.g. MYCN amplification status). In order to correct for multiple testing effects, the False Discovery Rate (FDR) method [30] is used for the adjustment of $p$-values.

\section{Software implementation}

The model has been implemented in a web server freely available at: http://hipathia.babelomics.org/.

Additionally, an R/Bioconductor script implementing the method is available at http://bioconductor.org/packages/devel/bioc/html/hipathia.html.

\section{Survival analysis}

Kaplan-Meier (K-M) curves [31] are used to relate module activity to patient survival in the different cancers. The value of the activity estimated for each module in each individual was used to assess its relationship with individual patient survival. Specifically, the $10 \%$ patients with higher (or lower) circuit activities are compared to the rest of individuals to test whether high (low) circuit activity is significantly associated to survival. Calculations were carried out using the function survdiff from the survival $\mathrm{R}$ package (https://cran.r-project.org/web/ packages/survival/). This method provides a $X^{2}$ statistic [32] that is used to calculate a $p$-value. Similarly to the case of two class comparison, multiple testing effects are corrected by FDR [30].

\section{Reviewers' comments}

Reviewer's report 1

Tim Beissbarth.

\section{Reviewer comments}

The manuscript describes an analysis on neuroblastoma data linking analysis of different pathways to molecular mechanisms in cancer and patient survival. Overall, this is an interesting and hypothesis driven modeling approach, that can better help to describe the functions of the cancer cell and thus leading to good survival models with a biological interpretation. However, I believe it also has some chances of over-fitting. I did not understand from the manuscript exactly how significance of their findings was assessed?

Author's response: The method recodes gene expression data into circuit (sub-pathway) activities. Then, differential activities between the conditions compared can be calculated. Significance is estimated in the same way differential gene expression significance is assessed. Here we use a Wilcoxon test. We have added a subsection to the methods section.

Some external validation on an independent data-set would be of help.

Author's response: The original HiPathia paper (Hidalgo et al., Oncotarget, 2017) contains several independent data validations.

Also comparison with other methods, either classical machine learning approaches or other pathway-structure oriented or classical gene set enrichment approaches might be interesting.

Author's response: Actually, we have recently published a benchmarking paper in which we demonstrate that Hipathia outperforms all competing methods (Amadoz et al., 2018, Briefings in Bioinformatics, In press). We have included a sentence at the end of the first paragraph in the Background section quoting this reference in the text.

Overall, I believe this is an interesting study and modeling approach and does have some merit. Of course, to be clinically relevant more validation and further studies would be needed.

Author's response: We cannot agree more, but obtaining clinically relevant results is outside the scope of this manuscript, that deals with the analysis of the Neuroblastoma CAMDA dataset and focuses on the throwing light on the molecular mechanisms of neuroblastoma.

If possible: - more detailed description of methods and statistical evaluation of significance - external validation on an independent data-set - comparison with other methods Critical points could also be discussed in the conclusion (to avoid overinterpretation or results).

Author's response: As mentioned above, we have added a new subsection to the Methods section to add more detail on the statistical validation of the values obtained. Comparison with other methods has been addressed in a separated paper and the result is that HiPathia outperforms the rest of pathway-based methods.

\section{Reviewer's report 2 \\ Wenzhong Xiao}

\section{Reviewer comments}

In this manuscript, Hidalgo etc. described their work using modeling to study cell signaling mechanisms of high-risk neuroblastoma and to predict disease outcomes. The paper is well written. Using Hipathia, an approach developed by the authors previously, they extracted comprehensively 1287 signaling circuits from 98 KEGG pathways and studied their activity in the neuroblastoma data. They first examined the impact of 
MYCN amplification on signaling pathways in neuroblastoma and it was comforting to see that the algorithm was able to identify well defined, reasonable signaling pathways affected by the MYCN amplification.

In particular, the authors identified a set of circuits in patients with MYCN amplification that inhibit the JNK cascade. They then systematically studied each of the signaling circuits and successfully identified those which activities were significant associated with patient outcomes. The study demonstrated the feasibility of using modeling of signaling pathway activity in studying disease mechanism and developing prognostic biomarkers.

Recommendations: 1. Page 3, line 54-55. Signal from RNA-seq data has a much wider distribution than that from array data, and usually a few genes have much higher expression than the rest. Can the authors clarify how the expression values were normalized between 0 and 1? In particular, according to eq. 1 on page 7 , would the few highest expression genes skew the Vn toward lower value for most of the genes?

Author's response: As we specified in methods we downloaded from the GEO database a matrix with gene expression levels normalized by FPKM and transformed as $\log 2(1+$ FPKM $)$ values. FPKM is a well-known and accepted normalization method for RNA-seq that accounts for sequencing depth and gene length. Finally, we re-scale the values between 0 and 1 because of HiPathia method requirements. In principle we did not observed biases due to lowly expressed genes in the gene expression values are properly normalized. Moreover, as commented, a benchmarking carried out by us pointed to HiPathia as the best performer of all the pathway based analysis methods.

Minor issues:

1. The figures, for some reason, appeared to have very low resolution. For example, in Fig. 1, the reviewer was not able to identify the proteins CCL19, CCL21 and GADD45B, nor the deactivation of these signaling circuits by NF-kappa B signaling as mentioned in text.

Author's response: Fig. 1 depicts only the deactivated circuits within the NF-kappa B signaling pathway. We have reformulated the text and the figure because it was a bit confusing before. We have clearly labeled the genes.

2. Page 4 , line 34 , and other places in the text. JackSTAT should be JAK-STAT.

Author's response: fixed.

Reviewer's report 3

Joanna Polanska.

\section{Reviewer comments}

The manuscript is devoted to study the activities of gene signaling pathways as triggers of neoplastic processes in neuroblastoma. The authors use their own computational algorithm, CCAA, previously published as [5], which enables assigning to KEGG signaling pathways a value, which describes its up or down regulation status. Activity states of gene signaling pathways are estimated on the basis of gene expression values obtained from the GEO data portal. The authors are able to demonstrate remarkable results, presented in Fig. 3, showing highly statistically significant differences between survivals of patients related to A) the status of inhibition of apoptosis via inhibition of a circuit of the Apoptosis pathway ending in the TP53 gene, B) the mechanism of activation of metastatic activity by activation of a circuit of the p53 signaling pathway ending in the THBS1 gene, C) the mechanism of activation of angiogenesis via the inhibition FASLG through the corresponding circuit in the PI3K-Atk signaling pathway, D) the mechanism of inhibition of apoptosis of B cells in the Neutrophin pathway that activates protein BAX. These mechanism are highly specific and extend the existing knowledge on the pathogenesis of neuroblastoma. In conclusion I recommend publication of the submitted manuscript without changes. Nevertheless, there are many interesting questions arising in regards to the manuscript, which the authors may wish to consider. Some of them are given below:

\section{Are there correlations between neuroblastoma patients concerning states of activation of their gene signaling pathways?}

Author's response: This is a very good question although including these results and commenting them is a bit away from the scope of this manuscript. Certainly, some circuits are correlated due to the dependence of some genes shared, which is an obvious correlation, but others not sharing genes are correlated as well, probably because they are under the same regulatory program. We have included a couple of sentences making reference to this comment at the end of the first paragraph of the Conclusions section.

\section{KM survival curves are quite asymmetric. Are there differences between survivals still seen if the group of patients is split into two equal size subgroups rather than in proportions $90 \%$ versus $10 \%$ ?}

Author's response: The idea was to discover these circuits remarkable related to survival. Therefore we had to clearly distinguish patients with high mortality rate from those with a low mortality rate and we thus focused on the extremes of the distribution. Splitting into two groups would reduce the detection sensitivity by including many patients with an intermediate survival in both groups. 


\section{Is it possible to relate pathogenic status of gene signaling pathways, discovered in the data, to somatic mutations in certain genes?}

Author's response: Probably, but there is no much information in TCGA regarding somatic mutations in neuroblastoma to reach solid conclussions.

\section{Is the aspect of multiple testing addressed in the computations?}

Author's response: Yes, actually FDR is used although was not explicitly stated in the text because we referred to the original publication. However, the referee is right in noting this absence and we have explained the correction used (FDR) in a new subsection within the Methods section.

\section{How one can image the computed status of gene signaling pathways in the context of cancer progression? Should one expect that the status of activation/inhibition changes during the evolution of cancer? Is it possible to observe some correlations with cancer pathogenic stages?}

Author's response: We are pretty sure that a time-series circuit activity study would reveal very interesting results. The only coarse grain approach to study time progression of circuit activities in cancer we did is in the original paper describing the method (Hidalgo et al., 2017) where we show how circuits corresponding to different cell functionalities changed across cancer stages. Some of them were initially activated in stage I and then remain with a similar activity, and we attributed them to cancer initiation functionalities, and some other increased its activity along cancer stages, and we guessed they were related to cancer progression cell functionalities.

\section{Additional files}

Additional file 1: Schema of signaling circuit definition. A) Different types of circuits can be defined within the pathways as subpathways that connect receptor proteins (those that receive the signal) to effector proteins (those at the end of the pathways). and ultimately to the functions behavioral outcomes triggered by the effector proteins. B) Elementary signaling circuits are defined as subpathways that connect a unique receptor to a unique effector protein; C) Effector circuits are defined as subpathways that connect a unique effector protein to all possible receptor protein that can start the transduction of signal; D) functional circuits are defined as subpathways that connect all the possible receptor proteins that can transduce signal to all the possible effector proteins that trigger a unique function. E) the concept of functional circuits is very convenient to define subsets of domain-specific functional circuits of relevance for the problem studied. For example, in cancer, the wellknown cancer hallmarks can be identified among the GO terms of the functions triggered by the effector proteins. (JPG $250 \mathrm{~kb}$ )

Additional file 2: Schema of the model of signaling circuit dynamics. A) The dynamics of the circuit is modeled taking the normalized gene expression values as proxies of protein activation status (the more expressed is a gene. The more likely the corresponding gene product will be active); B) given that both activations and repression activities can occur along the pathway, different scenarios are considered for the transmission of the signal: only activation, simultaneous activation and inhibition and only inhibition, which are coded in the formula; C) the application of the formula provided estimations of the different fluxes of signal across the circuit that finally arrive to the effector protein. In this way, a gene expression profile can be transformed in the corresponding signaling circuit activity profile (or functional profile). (JPG $149 \mathrm{~kb}$ )

\section{Abbreviations}

FDR: False Discovery Rate; FPKM: Fragments Per Kilobase of transcript per Million; KEGG: Kyoto Encyclopedia of Genes and genomes; K-M: Kaplan-Meier curves

\section{Funding}

This work is supported by grants BIO2014-57291-R and SAF2017-88908-R from the Spanish Ministry of Economy and Competitiveness and "Plataforma de Recursos Biomoleculares y Bioinformáticos" PT13/0001/0007 from the ISCIII, both co-funded with European Regional Development Funds (ERDF); and EU H2020-INFRADEV-1-2015-1 ELIXIR-EXCELERATE (ref. 676559) and EU FP7-People ITN Marie Curie Project (ref 316861).

Availability of data and materials

Data sharing is not applicable to this article as no datasets were generated or analysed during the current study.

Authors' contributions

MRH developed the method and carried out part of the analysis; AA, CC, JC$\mathrm{C}$ carried out different parts of the analysis and interpretation of the results; JD conceived the work and wrote the paper. All authors read and approved the final manuscript.

Ethics approval and consent to participate Not applicable.

Consent for publication

Not applicable.

Competing interests

The authors declare that they have no competing interests.

\section{Publisher's Note}

Springer Nature remains neutral with regard to jurisdictional claims in published maps and institutional affiliations.

\section{Author details}

${ }^{1}$ Clinical Bioinformatics Area, Fundación Progreso y Salud (FPS), CDCA, Hospital Virgen del Rocio, c/Manuel Siurot s/n, 41013 Sevilla, Spain. ${ }^{2}$ Igenomix S.A. Ronda Narciso Monturiol, 11 B, Parque Tecnológico Paterna, 46980 Paterna, Valencia, Spain. ${ }^{3}$ Centre for Genomic Regulation, Carrer del Dr. Aiguader, 88, 08003 Barcelona, Spain. ${ }^{4}$ Functional Genomics Node (INB). FPS, Hospital Virgen del Rocio, c/Manuel Siurot s/n, 41013 Sevilla, Spain. ${ }^{5}$ Bioinformatics in Rare Diseases (BiER), Centro de Investigación Biomédica en Red de Enfermedades Raras (CIBERER), FPS, Hospital Virgen del Rocio, c/ Manuel Siurot s/n, 41013 Sevilla, Spain.

Received: 9 October 2017 Accepted: 8 August 2018

Published online: 22 August 2018

References

1. Brodeur GM. Neuroblastoma: biological insights into a clinical enigma. Nat Rev Cancer. 2003;3(3):203-16.

2. Øra I, Eggert A. Progress in treatment and risk stratification of neuroblastoma: Impact on future clinical and basic research. Semin Cancer Biol. 2011;21(4):217-8

3. Fey D, Halasz M, Dreidax D, Kennedy SP, Hastings JF, Rauch N, Munoz AG, Pilkington R, Fischer M, Westermann F, et al. Signaling pathway models as biomarkers: Patient-specific simulations of JNK activity predict the survival of neuroblastoma patients. Sci Signal. 2015;8(408):ra130. 
4. Hanahan D, Weinberg RA. Hallmarks of cancer: the next generation. Cell. 2011;144(5):646-74.

5. Hidalgo MR, Cubuk C, Amadoz A, Salavert F, Carbonell-Caballero J, Dopazo J. High throughput estimation of functional cell activities reveals disease mechanisms and predicts relevant clinical outcomes. Oncotarget. 2017:8(3):5160-78

6. Amadoz A, Hidalgo M, Cubuk C, Carbonell-Caballero J, Dopazo J. A comparison of mechanistic signaling pathway activity analysis methods. Brief Bioinform. 2018; In press

7. Johnson WE, Li C, Rabinovic A. Adjusting batch effects in microarray expression data using empirical Bayes methods. Biostatistics. 2007;8(1):118-27.

8. Huang R, Cheung N-KV, Vider J, Cheung IY, Gerald WL, Tickoo SK, Holland EC, Blasberg RG. MYCN and MYC regulate tumor proliferation and tumorigenesis directly through BMI1 in human neuroblastomas. FASEB J. 2011;25(12):4138-49.

9. Lin XD, Chen SQ, Qi YL, Zhu JW, Tang Y, Lin JY. Overexpression of thrombospondin-1 in stromal myofibroblasts is associated with tumor growth and nodal metastasis in gastric carcinoma. J Surg Oncol. 2012; 106(1):94-100

10. Manda KR, Tripathi P, Hsi AC, Ning J, Ruzinova MB, Liapis H, Bailey M, Zhang $\mathrm{H}$, Maher CA, Humphrey PA. NFATC1 promotes prostate tumorigenesis and overcomes PTEN loss-induced senescence. Oncogene. 2016;35(25):3282.

11. Motz GT, Coukos G. The parallel lives of angiogenesis and immunosuppression: cancer and other tales. Nat Rev Immunol. 2011; 11(10):702.

12. Murdoch C, Muthana M, Coffelt SB, Lewis CE. The role of myeloid cells in the promotion of tumour angiogenesis. Nat Rev Cancer. 2008;8(8):618.

13. Choudhuri T, Pal S, Agwarwal ML, Das T, Sa G. Curcumin induces apoptosis in human breast cancer cells through p53-dependent Bax induction. FEBS Lett. 2002;512(1-3):334-40.

14. Chan G, Kalaitzidis D, Neel BG. The tyrosine phosphatase Shp2 (PTPN11) in cancer. Cancer Metastasis Rev. 2008;27(2):179-92.

15. Mandai K, Rikitake Y, Shimono Y, Takai Y. Afadin/AF- 6 and canoe: roles in cell adhesion and beyond. Prog Mol Biol Transl Sci. 2013;116:433-54.

16. Kholodenko B, Yaffe MB, Kolch W. Computational approaches for analyzing information flow in biological networks. Sci Signal. 2012;2002961:re1.

17. Kholodenko BN, Hancock JF, Kolch W. Signalling ballet in space and time. Nat Rev Mol Cell Biol. 2010;11(6):414.

18. Jiang B, Gribskov M. Assessment of subnetwork detection methods for breast cancer. Cancer Informat. 2014;13(Suppl 6):15.

19. Falco MM, Bleda M, Carbonell-Caballero J, Dopazo J. The pan-cancer pathological regulatory landscape. Sci Rep. 2016;6:39709.

20. Fryburg DA, Song DH, Laifenfeld D, de Graaf D. Systems diagnostics: anticipating the next generation of diagnostic tests based on mechanistic insight into disease. Drug Discov Today. 2014;19(2):108-12.

21. Salavert F, Hidalgo MR, Amadoz A, Cubuk C, Medina I, Crespo D, CarbonellCaballero J, Dopazo J. Actionable pathways: interactive discovery of therapeutic targets using signaling pathway models. Nucleic Acids Res. 2016;44(W1):W212-6.

22. Dopazo J. Genomics and transcriptomics in drug discovery. Drug Discov Today. 2014;19(2):126-32.

23. Trapnell C, Roberts A, Goff L, Pertea G, Kim D, Kelley DR, Pimentel H, Salzberg SL, Rinn JL, Pachter L. Differential gene and transcript expression analysis of RNA-seq experiments with TopHat and cufflinks. Nat Protoc. 2012;7(3):562-78.

24. Kanehisa M, Goto S, Sato Y, Kawashima M, Furumichi M, Tanabe M. Data information, knowledge and principle: back to metabolism in KEGG. Nucleic Acids Res. 2014;42(Database issue):D199-205.

25. Sebastian-Leon P, Vidal E, Minguez P, Conesa A, Tarazona S, Amadoz A, Armero C, Salavert F, Vidal-Puig A, Montaner D, et al. Understanding disease mechanisms with models of signaling pathway activities. BMC Syst Biol. 2014;8(1):121

26. Efroni S, Schaefer CF, Buetow KH. Identification of key processes underlying cancer phenotypes using biologic pathway analysis. PLoS One. 2007;2(5):e425

27. Montaner D, Minguez P, Al-Shahrour F, Dopazo J. Gene set internal coherence in the context of functional profiling. BMC Genomics. 2009; 10(1):197.

28. Ashburner M, Ball CA, Blake JA, Botstein D, Butler H, Cherry JM, Davis AP, Dolinski K, Dwight SS, Eppig JT, et al. Gene ontology: tool for the unification of biology. The Gene Ontology Consortium. Nat Genet. 2000;25(1):25-9.
29. UniProt_Consortium. UniProt: a hub for protein information. Nucleic Acids Res. 2015:43(Database issue):D204-12.

30. Benjamini Y, Hochberg Y. Controlling the false discovery rate: a practical and powerful approach to multiple testing. J Royal Stat Soc Series B. 1995; 57(1):289-300

31. Kaplan E, Meier P. Nonparametric estimation from incomplete observations. J Am Stat Assoc. 1958;53(282):457-81.

32. Harrington DP, Fleming TR. A class of rank test procedures for censored survival data. Biometrika. 1982;69(3):553-66.

\section{Ready to submit your research? Choose BMC and benefit from:}

- fast, convenient online submission

- thorough peer review by experienced researchers in your field

- rapid publication on acceptance

- support for research data, including large and complex data types

- gold Open Access which fosters wider collaboration and increased citations

- maximum visibility for your research: over $100 \mathrm{M}$ website views per year

At BMC, research is always in progress.

Learn more biomedcentral.com/submissions 